\title{
Protagonismo infantil: co-construindo significados em meio às práticas sociais
}

\author{
Sergio Fernandes Senna Pires \\ Angela Uchoa Branco \\ Universidade de Brasília, Brasília-DF, Brasil
}

Resumo: Neste artigo discutem-se as conceituações de protagonismo infantil e as possibilidades de participação das crianças na sociedade, diante das práticas sociais relacionadas à institucionalização da infância e à separação entre crianças e adultos. A partir da construção social do conceito de infância, baseado na pressuposição da incapacidade e da incompletude infantis, analisam-se os possíveis níveis de participação infantil nos processos decisórios. Concluise que uma abordagem socio-histórico-cultural permite compreender como o desenvolvimento do conceito de infância e a adoção de outros critérios poderão promover maior aproximação entre crianças e adultos e suas formas de compartilhar projetos, responsabilidades e compromissos.

Palavras-chave: Participação infantil. Protagonismo infantil. Conceito de infância. Visibilidade infantil.

\section{Children's participation: co-constructing meaning within social practices}

\begin{abstract}
In this article, the meaning of child participation and his/her effective possibility to take initiatives concerning social practices are discussed considering the institutionalization of childhood and children's segregation from the "adult world". Starting from the social construction of the childhood concept, based on the assumption of children inabilities and incapacities, follows a discussion concerning the possible different levels of children participation in decision making. From a sociocultural-historical approach, it is possible to understand how the development of the 'childhood' concept and the adoption of different criteria may promote a closer approach between children and adults and the sharing of projects, responsibilities and commitments.
\end{abstract}

Keywords: Children participation. Concept of childhood. Institutionalization of childhood. Child visibility.

\section{Protagonismo infantil: co-construyendo significados en el medio as prácticas sociales}

Resumen: En este artículo se discute los conceptos del protagonismo infantil y las posibilidades de participación de los niños en la sociedad, mediante las prácticas sociales relacionadas a institucionalización de la infancia y la separación entre los niños y los adultos. A partir de la construcción social del concepto de infancia, basado en la presuposición de incapacidad e in complejidad infantil, se analizan los posibles niveles de la participación infantil en los procesos decisorios. Concluye que un abordaje socio-cultural-histórico permite comprender como el desarrollo del concepto de infancia y la adopción de otros criterios podrá promover mayor aproximación entre los niños y los adultos y sus formas de compartir proyectos, responsabilidades y compromisos.

Palabras clave: Participación infantil. Concepto de infancia. Institucionalización de la infancia. Visibilidad infantil. 


\section{Protagonismo ou participação infantil? Processos decisórios e visibilidade em questão}

Ao referir-se à forma como os adultos do início do século XX entendiam a infância, com toda a propriedade, Korczak (1919/1984, p. 95) aborda um dos elementos centrais quando se trata de assumir um papel de protagonismo em um contexto social:

E a nossa abordagem da infância, não será reveladora do egocentrismo do adulto? Educados na escravatura, incapazes de transformar a vida, como poderíamos dar liberdade aos nossos filhos? Deveríamos, em primeiro lugar, libertar-nos das nossas próprias amarras.

O paradoxo com o qual iniciamos este artigo (como um servo pode conceder liberdade?) será abordado tomando-se em conta a necessidade de estudarmos o protagonismo infantil, seus possíveis significados, níveis de exercício e as perspectivas que promovem ou restringem as suas possibilidades.

$\mathrm{O}$ que vem a ser protagonismo infantil? Existem diferenças entre protagonismo e participação? Considerando-se as práticas sociais associadas à infância, sua institucionalização, separação do "mundo adulto", será possível promover a participação real das crianças? Que nível de participação é possível? Estas são questões que nortearam a elaboração deste artigo.

A origem etimológica do termo remete à palavra protagonistés que, no idioma grego, significava o ator principal de uma peça teatral, ou aquele que ocupava o lugar principal em um acontecimento (Ferreira, 2004). As restrições mais comuns em relação ao uso desse termo, no jargão sociológico, se devem a fatores de ordem política, uma vez que a utilização alternativa da palavra 'participação' parece sugerir "uma abordagem mais democrática na ação social, sem colocar em destaque um protagonista singular" (Ferretti, Zibas \& Tartuce, 2004, p. 3).

Entretanto, os autores enfatizam que, na revisão bibliográfica realizada sobre o tema, encontraram diferentes interpretações dos termos protagonismo e participação, o que demonstra o verdadeiro caráter polissêmico da expressão. Por ser um conceito passível de diferentes interpretações e imbricado com outros conceitos igualmente polissêmicos, como participação, responsabilidade social, identidade, autonomia e cidadania, a argumentação acerca da impropriedade de sua utilização perde o sentido. Afirmam que nem mesmo a distinção conceitual entre participação e protagonismo ficou clara na bibliografia que consultaram, concluindo que um autor pode se referir ao protagonismo em contextos em que outro falaria de participação, e vice-versa, havendo, ainda, casos em que as duas expressões são usadas como sinônimos.

Apesar da polêmica em relação ao emprego dos termos participação e protagonismo, parece haver duas vantagens óbvias quanto à utilização preferencial da palavra participação. A primeira se refere à facilidade do emprego do vocábulo por crianças, uma vez que, em uma primeira análise, a palavra participação é um termo de uso corrente na língua portuguesa. A segunda vantagem se refere a maior facilidade para explicar o que é participação (com o significado de protagonizar) para as crianças, no contexto de programas ou campanhas que visem promover o seu envolvimento nos processos decisórios para transformações sociais.

Shier (2001) argumenta que a produção acadêmica sobre o assunto tomou um grande impulso a partir dos anos 1990 e que a participação infantil e seus desdobramentos teóricos vêm ganhando espaço nas práticas de sua promoção entre a população infantil ao redor do mundo (Adams \& Ingham, 1998; Crowley, 1998; Hart, 1992; Save the Children, 1996; Shier, 1996; Treseder, 1997; Willow, 1997).

Destaca, ainda, o trabalho pioneiro de Hart (1992, 1997), que influenciou uma grande parte dos trabalhos ulteriores. Em seus estudos, Hart afirma que não existem sociedades que ofereçam, o tempo todo, a máxima oportunidade de participação para as crianças. Esta constatação não parece muito surpreendente, tendo em vista que é virtualmente impossível, considerando-se que o sistema político que serve de contexto é um sistema democrático, que algum grupo exerça o máximo de influência o tempo todo. É esperado, portanto, que diversos grupos se revezem nos momentos nos quais são exigidos alguns tipos específicos de participação (Sinclair, 2004; Soares, Sarmento \& Tomás, 2004).

Shier (2001) explica que Hart dividiu suas oito categorias de participação em dois grupos: as três 
primeiras são aquelas em que não se pode considerar uma efetiva participação infantil. Consistem na manipulação, na memorização e no envolvimento simbólico. As cinco categorias restantes agrupam os elementos da participação e suas denominações, destacando a variação da iniciativa da proposta e da condução das ações. Na proposta de Hart (1997) estas categorias se encontram hierarquizadas em oito níveis progressivos de participação infantil. Toda a sua argumentação se desenvolve no sentido de que o maior grau de autonomia exercido pelas crianças é o mais desejável e mais complexo.

Apesar de apresentar aspectos teóricos relevantes para a reflexão acerca da participação infantil, entendemos que a categorização hierárquica, necessariamente, não reflete a realidade do exercício da participação por parte das crianças, o que já vem sendo apontado por diversos autores (Kirby, Lanyon, Cronin, \& Sinclair, 2003; Shier, 2001; Sinclair, 2004). Além disso, confundir participação (em uma versão radicalmente protagônica) com predominância seria cometer erro semelhante ao de um sistema cujos processos decisórios sejam apoiados exclusivamente em adultos.

Partindo-se de um pressuposto de que as relações se estabelecem de forma sistêmica ou ecológica (Bronfenbrenner, 1986) existem diversas configurações possíveis para as relações que se estabelecem entre crianças e adultos na execução de um projeto ou mesmo durante o debate de idéias. Essas relações não são simétricas e acaba por existir algum grupo que predomina ou detém o poder (Bourdieu, 1989; Foucault, 1984; MacLaren, 1997). Observa-se, especialmente, que as relações de poder que se estabelecem nos ambientes escolares poderão servir de ambiente para a promoção da participação infantil, ou seja, o envolvimento ativo nos processos decisórios coletivos de uma parcela da população que, historicamente, por ter menor idade, foi segregada e afastada das práticas decisórias referentes à organização e dinâmica da vida social (Ariès, 1978; Kramer, 2003; Kramer \& Leite, 1996). Além disso, existem práticas sociais relativamente consolidadas que promovem um conjunto de interdições e de prescrições que sucessivamente negam ações, capacidades ou poderes às crianças (Bujes, 2000; Sarmento, 2005), o que será posteriormente detalhado.
Assumindo que se deseja promover a participação infantil e considerando a complexidade dos possíveis arranjos de tarefas, decisões, níveis de abstração e estado desenvolvimental necessários para a tomada de decisões, avaliação de conseqüências, exercício de competências técnicas, suprimento de necessidades econômicas, atendimento a aspectos jurídicos, entre tantos outros que poderiam ser levantados, a configuração mais provável é que haja diferentes arranjos complexos em relação à partilha de responsabilidades, compromissos e, conseqüentemente, o desempenho de diferentes tarefas entre crianças e adultos.

O compartilhamento da responsabilidade, por apresentar soluções no contexto de um processo decisório cujo objetivo é lograr a ampla participação de todos, é bastante complexo (Escámes \& Gil, 2003; Novaes, 2000). As propostas abstratas e a responsabilidade por disponibilizar os meios para a realização das ações concretas, de algum modo, precisam ser compatibilizadas. Por isso, hierarquizar os tipos de participação, ainda que sob a alegação de categorização para fins acadêmicos, é impróprio. Uma vez que nos processos decisórios estão envolvidas competências distintas, recursos de diversas ordens, motivos, conhecimentos, percepções, normas, é muito mais aceitável pensar que haverá um fluxo de compromissos e propostas que se alternará entre crianças e adultos, conforme as possibilidades de contribuição e cooperação dos diferentes grupos.

Diante disso, não há sentido em hierarquizar, $a$ priori, níveis de participação tomando-se por base a iniciativa ou a responsabilidade pela condução das ações, pois o que realmente importa é como se realiza o processo decisório e quais são os compromissos assumidos entre todos os atores. Sob o ponto de vista do processo decisório, interessa garantir a ampla participação, entendendo-se que, caso a caso, haverá limitações segundo as quais crianças ou adultos sobressairão em determinado momento.

A apresentação da forma como diversos autores definem o protagonismo ou a participação serve para levar à conclusão de que a ação social, e a preparação para esse tipo de ação, se constituem nos principais elementos semânticos que os textos pretendem comunicar através das expressões que afirmam: a criança como ser autônomo é capaz de 
incentivar ações e decisões importantes no contexto de atividades relevantes. Mas será que as práticas sociais atuais cooperam para que as crianças se afirmem como seres participativos no contexto social?

\section{A construção histórico-cultural do conceito de infância}

$\mathrm{Na}$ segunda década do século XX, Janusz Korczak resolveu registrar a sua percepção acerca da acentuada separação entre o mundo das crianças e o mundo dos adultos. Nesta época já era possível notar os indicadores de uma nova forma de significar e viver a infância.

Se dividíssemos a humanidade em crianças e adultos, e a vida em dois períodos, o da infância e o da maturidade, compreenderíamos que as crianças ocupam um enorme espaço no mundo e na vida. Mas, demasiado absorvidos pelos nossos próprios problemas, não as observamos, tal como antigamente nós não nos apercebíamos da existência da mulher, dos camponeses, das classes e dos povos oprimidos (Korczak, 1919/1984, p. 88, grifos nossos).

Neste campo cabe ao trabalho pioneiro de Ariès o mérito de ter inaugurado um estudo sistemático acerca da história da infância. Situada como um acontecimento caracteristicamente moderno, imerso em uma série de condições que se conjugam e que estabelecem novas possibilidades de compreensão de um fenômeno que, apesar de apresentar uma dimensão biológica, a infância é um fato cultural por excelência (Ariès, 1978; Bujes, 2000).

Segundo Bujes (2000), o mérito de Ariès foi demonstrar que houve profundas mudanças nas atitudes e nos sentimentos das pessoas em relação às crianças. Essas mudanças acabaram por serem incorporadas às práticas sociais e à construção dos significados, fazendo emergir um conceito de infância que se consolidou a partir do século XVII e que influiu decisivamente para que fosse dado um destaque muito especial a esse momento da vida humana.

As fontes de dados utilizadas por Ariès inspiram cuidado quanto à generalização de conclusões construídas a partir delas, uma vez que a maior parte, como descreve o próprio autor, é de origem francesa. Portanto, há que se ter especial cuidado, principalmente se o propósito é realizar uma análise sob o ponto de vista histórico-cultural, uma vez que, nessa abordagem, não há categorias universais. É certo que a infância africana ou a infância asiática, ou mesmo a infância no semi-árido da Região Nordeste do Brasil poderá não se assemelhar ao argumentado por Ariès (1978). No entanto, esta constatação somente poderá ser analisada caso a caso, estudando-se a questão da "infância" nas diferentes culturas.

A infância na Idade Média européia era vivenciada em um cenário bastante complexo e extremamente distinto do atual, em termos dos critérios de passagem para a idade adulta. Ariès (1978) argumenta que um dos temas prediletos do escritor medieval eram as "idades da vida", segundo as quais o termo infância se referia aos primeiros sete anos de vida.

Outro fenômeno que influenciava as práticas socioculturais medievais era a elevadíssima mortalidade infantil, o que, segundo Ariès, estabelecia uma relação de causa e efeito entre o período crítico no qual a criança corria um maior risco de falecer e a sua passagem para a vida adulta. Assim que superava esse período no qual a sua sobrevivência era improvável, ela se confundia com os adultos.

Além disso, as idades da vida não correspondiam apenas a etapas biológicas, mas estavam intimamente relacionadas com a capacidade das crianças se inserirem no trabalho, nas atividades adultas e no exercício de funções sociais. A duração da infância era reduzida apenas ao seu período mais frágil. A partir do seu término, havia uma grande interação com os adultos e as crianças-em-transição aprendiam as coisas que deviam saber ajudando os adultos a fazê-las (Ariès, 1978; Gélis, 1991).

A alteração do cenário que existia na Idade Média e a constituição das práticas a partir das quais se define modernamente a infância, se deu a partir da transição do século XVII para o XVIII e se prolongou até o século XIX. Fundamentada em pressupostos filosóficos de ordem moralista e religiosa, a concepção de infância àquela época passou a enfatizar a ingenuidade e fragilidade do ser humano (Ariès, 1978; Gélis, 1991). Segundo os autores, a dinâmica dessa alteração iniciou-se em meio às práticas de 
mimar e paparicar as crianças, dando início a uma fase em que o cuidado com esses pequenos seres seria crescentemente enfatizado até os dias atuais. Adultos e crianças se diferenciam cada vez mais com o objetivo de garantir os mitos da inocência, da excessiva vulnerabilidade, e da incapacidade, cujos efeitos se fazem sentir nos dias atuais, o que é apontado em estudos recentes (Checkoway, Kameshwari \& Finn, 1995; Francis \& Lorenzo, 2002; Hill, Davis, Prout \& Tisdall, 2004; Matthews, Limb \& Taylor, 1999).

O critério cronológico para caracterização da infância surgiu a partir de duas necessidades: de utilizar um parâmetro preciso para identificar as pessoas e pelo estabelecimento progressivo de uma relação biunívoca entre a idade e a etapa de escolarização (Ariès, 1978). A idade se tornou uma quantidade juridicamente mensurável, com precisão de horas. A necessidade em assumir uma personalidade jurídica ao longo da vida, transferir bens, sofrer sanções, entre outros aspectos legais reforçou a adoção desse critério (Foucault, 1984; Gélis, 1991). Além disso, a criança começou a permanecer mais tempo na escola, deixando de conviver, nesse momento, com os adultos de sua família e de aprender a vida diretamente por meio do trabalho ou da realização das tarefas, que outrora serviam de parâmetro para passagem da infância à vida adulta.

Além disso, a crescente preocupação com o bem estar das crianças e o grande esforço realizado pelas famílias em não aceitar a "fatalidade" da mortalidade infantil, passou a ser um objetivo dos pais, o que contribuiu para a rápida difusão de elementos necessários à construção da nova concepção sobre a excessiva fragilidade da infância e dos conseqüentes cuidados especiais que seriam necessários (Gélis, 1991).

Com relação à necessidade da diferenciação entre os indivíduos, Frones (conforme citado por Montandon, 2001) observa um curioso paradoxo relacionado à invasão da vida infantil por esse rigoroso controle social e por uma regulamentação maciça no domínio da educação e dos cuidados profissionais. A dinâmica social moderna exige que esse controle burocrático (necessidade de identidade única a partir do nascimento para o exercício do direito de possuir, por exemplo) se dê sobre o indivíduo, o que, hipoteti- camente, promoveria a sua diferenciação e autonomia. No entanto, esta suposta autonomia é acompanhada por um brutal controle social que é exercido sobre os seres humanos, entre eles as crianças. Esta mesma constatação é confirmada pelo trabalho de Cruz, Hillesheim e Guareschi (2005) e anteriormente observada por Foucault (1984).

A educação, então, se tornou o principal espaço institucional para organizar a vida das crianças. Esta influência institucional foi chamada por Ariès de "quarentena" e iniciou um "longo processo de enclausuramento das crianças (como dos loucos, dos pobres e das prostitutas) que se estende até os nossos dias, e ao qual se dá o nome de escolarização" (Aires, 1978, p. 11).

Sarmento (2004, 2005), com relação à disciplina, explica que as escolas impõem o que chamam de "ofício de criança". É um universo próprio de normas que servem para organizar o desempenho social das crianças, onde são conduzidos processos de socialização vertical, imposição de normas, idéias, crenças e valores que são predominantemente construídos sob o ponto de vista do adulto (McLaren, 1997; Sarmento, 2005).

Nesse contexto, o conceito sociológico atual de infância se constrói a partir da formação de um corpo de especialistas, da institucionalização da escola, bem como do desenvolvimento de teorias e de técnicas específicas para lidar com as crianças. Nos Estados nacionais europeus, surgidos a partir da queda da sociedade feudal, foram estabelecidas regras, expectativas, possibilidades e limites para todos os indivíduos, que, de certa forma, serviram de contexto para essas transformações.

A formação de um corpo de especialistas sobre a criança é um aspecto relevante, uma vez que aumenta o risco da ocorrência de uma separação mais evidente entre crianças e adultos. Já que há alguém que sabe tanto sobre ela, para que escutá-la diretamente?

Sarmento (2005) se refere à construção da infância, a partir de processos historicamente consolidados na negação de determinadas características ou condições, categoria ou aspecto da sociedade a um grupo. Segundo sua argumentação, as crianças foram pensadas e reguladas, na modernidade, a partir de um conjunto de interdições e de prescrições que sucessivamente negam ações, capacidades ou 
poderes às crianças e, como afirma Bujes (2000, p. 28), "sobretudo inseri-las em processos de controle e regulação cada vez mais sofisticados, porque invisíveis e consentidos".

Tornando-se os corpos e mentes das crianças objeto da ciência, proliferou o conhecimento acerca desses pequenos seres. Bujes (2000) afirma que o saber produzido com base nesse processo promove dois efeitos complementares que se reforçam mutuamente: "descreve os processos pelos quais passam os sujeitos infantis no seu desenvolvimento (descrevendo o que é normal e desejável neste desenvolvimento) e, ao mesmo tempo, serve de referência para que tais processos sejam observados e avaliados" (Bujes, 2000, p. 29).

As crianças possuem características próprias ao seu momento desenvolvimental, o que não as tornam menos competentes enquanto atores sociais nem seres incompletos ou imperfeitos, mas caracterizam elementos configuradores de um grupo singular na existência humana (Qvortrup, 1991, 1995; Sarmento, 2000, 2001, 2003).

No entanto, ainda que a concepção atual de infância promova a invisibilidade e afonia infantis, as crianças seguem participando ativamente da construção cultural (Boto, 2002, p. 57).

Encontra-se um quê de silêncio, de separação, de isolamento, e também de invisibilidade. A criança é muda; em sua individualidade, é espectador silencioso; é silenciada em sua voz, que, pelo suposto moderno, não saberá falar por si. A criança dita pela razão moderna foi desencantada; sem dúvida. Foi secularizada e institucionalizada. (...) Ao separar a criança do universo adulto, a modernidade cria a infância como uma mônada - unidade substancial ativa e individual; presente, no limite, em todos os seres infantis da espécie humana: sempre a mesma; sempre igual, inquebrantável, inamovível, irredutível - um mínimo denominador comum. Não falamos mais das crianças, e sim da infância.

Expressam-se de formas diferenciadas a interpretação, simbolização e comunicação das suas percepções do mundo. Ao interagirem com seus pa- res e com adultos, se envolvem nas mais variadas ações nos espaços público e privado. Oswald (1992), por exemplo, estudou a negociação e a criação de complexos conjuntos de normas entre crianças, concluindo sobre a grande capacidade infantil em lidar com elementos simbólicos. Estudos como este demonstram que as culturas infantis, historicamente posicionadas no tempo e no espaço, não são reproduções, em verdadeira grandeza, de culturas adultas, nem são uma versão imperfeita ou em miniatura do que existe no ambiente social. São fruto de um complexo processo de co-construção para o qual as crianças estão mais do que preparadas para iniciar a sua caminhada ao lado dos adultos.

No entanto, a institucionalização dos cuidados com a criança, bem como a grande quantidade de tempo que passam envolvidas com a escola se tornaram impedimentos para a participação infantil, tendo em vista o grau de controle exercido pelos adultos e a pouca influência que as crianças possuem sob seus próprios ambientes. Apesar disso, a escola poderia ser um espaço privilegiado para o exercício da participação e de tudo o que antes ocorria nos espaços sociais comuns e no trabalho. Procurando reagir a esse saber produzido durante o transcorrer do século XX, como lembra Sarmento (2005), as principais abordagens teóricas atuais sobre a infância desenvolvem suas atividades de forma a pesquisar a competência infantil, considerando a sua legítima experiência, as suas oportunidades de vida e os seus ambientes. Uma nova forma de significar a infância, apoiada nas possibilidades, suas características particulares e sob o ponto de vista do momento vivido é fundamental para a superação dos estudos baseados na incapacidade e incompletude infantis.

\section{Participação infantil, escolarização e controle social}

Escolarização, controle social e os critérios modernos de infância se imbricam. As revoluções demográfica, econômica e social que ocorreram a partir do século XVII, serviram de contexto para que a escola se estabelecesse como um lugar de cuidado da infância. As crianças, que antes aprendiam a realizar as suas tarefas em um contexto laboral ao lado dos adultos, passaram a freqüentar a escola, esse novo local de aprendizagem, que logo se tornou, no mundo ocidental, um espaço para a imposição de disciplina. 
Estava então iniciada a separação do mundo adulto do mundo das crianças a que se refere Janusz Korczak e ao que Ariès (1978) chamou de "quarentena", e Sarmento (2005), de "ofício de criança".

$\mathrm{Na}$ sociedade ocidental, foi se difundindo a percepção de que a criança não estava madura para a vida e que era um ser do futuro. Conseqüentemente, surgiu a compreensão de que as crianças precisavam de um regime especial de preparação para o ingresso na vida adulta, o que auxiliou e agilizou o estabelecimento desse sistema de aprendizagem. Pouco a pouco, a partir do século XVIII até os dias atuais, foi se estabelecendo uma relação entre a idade das crianças e a série escolar que deveriam estar cursando.

A ênfase no critério cronológico para a passagem à vida adulta teve os seus primeiros momentos na confluência desse fenômeno com o surgimento da necessidade do gerenciamento da vida sob o ponto de vista jurídico. O surgimento do Estado-nação, a adoção de sistemas republicanos e democráticos necessitava da codificação de normas para o exercício de direitos de um grande número de cidadãos. Sem uma solução alternativa para a garantia de direitos, os países se lançaram numa produção legislativa desenfreada. Para que essas leis tivessem a sua eficácia garantida, as pessoas precisavam ser diferenciadas umas das outras. A articulação entre os critérios cronológico, datiloscópico e, recentemente, os métodos de identificação genética constitui-se em estratégia metodológica utilizada nessa individuação. A idade cronológica é uma dimensão facilmente mensurável e extremamente útil para a aplicação de condições jurídicas.

No entanto, observa-se um paradoxo nesse contexto. A necessidade de individuação das pessoas para efeito do exercício de seus direitos coexiste com um forte controle social que oferece fortes sugestões no sentido de promover imposição relativamente padronizada de crenças e valores (Hardman, 2001; Qvortrup, 1995).

A par do processo de individuação e durante o decorrer do século XX, o tempo que a criança passava na escola foi aumentando, assim como também foi incrementada a quantidade de anos que, obrigatoriamente, alguém deveria freqüentar o ensino fundamental. Recentemente, no Brasil, aumentou-se de oito para nove os anos escolares obrigatórios. Este contexto, no qual as crianças passam, no mínimo, cinco horas diárias é ideal para a condução de estratégias de disciplina e construção dirigida de significados. E aí, este contexto torna-se capaz tanto de gerar imposições e canalizações de regras e valores, como também de promover a crítica, a flexibilidade simbólica e a criatividade entre os alunos. Entretanto, o controle social que se estabeleceu sobre as crianças, suas formas, seus níveis e suas articulações não lhes deixou muito espaço.

A admissão do pressuposto que a criança não está madura para a vida, e que é necessário submetêla a um regime especial antes de permitir o seu ingresso na vida adulta vem promovendo o conseqüente prolongamento da infância em sincronia com a duração da escolarização obrigatória. Não seria essa uma forma indireta de também prolongar o período em que prevalece a concepção de inaptidão e incompletude da criança?

Os princípios que sustentam a participação infantil indicam que é necessário investir na autonomia infantil, o que não significa incentivar o surgimento de pequenos tiranos, nem a submissão dos adultos à vontade das crianças. Pensar desta forma seria inverter a situação que hoje se verifica sem nenhum ganho desenvolvimental ou social. A verdadeira autonomia é regulada por um compromisso recíproco entre os sujeitos (Rogoff, 1995).

É muito mais produtivo imaginar um sistema complexo de interações que se configura em torno da iniciativa e das responsabilidades compartilhadas durante a condução do processo decisório de realização das ações de um determinado projeto. Crianças e adultos assumirão responsabilidades diferentes (nem por isso necessariamente menos importantes) ao longo de todos os momentos, desde o surgimento de uma idéia, sua discussão e realização. No entanto, é necessário alertar que os critérios utilizados atualmente para separar o mundo entre crianças e adultos não facilitam este tipo de configuração e compartilhamento de responsabilidade e compromissos.

Os estudos que tratam das relações entre pares e sobre as trocas e brincadeiras entre crianças foram os que promoveram uma tomada de consciência sobre a debilidade dos paradigmas que conceituavam as crianças como objetos da ação dos adul- 
tos. Destacam-se, por exemplo, os trabalhos realizados por Corsaro (Corsaro, 1979; Corsaro \& Eder, 1990; Corsaro \& Miller, 1992). Em um de seus estudos, Corsaro (1986) concluiu que, quando as crianças interagem representando papéis e deixam a sua imaginação livre, por um lado tentam adquirir certo controle sobre suas próprias vidas, e por outro compartilham esse controle entre os pares.

A partir do interesse pelo papel que a linguagem desempenha na construção de significados (Bruner, 1997; Valsiner, 2005), Montandon (2001) apresenta o estudo de Maynard (1986) cuja principal conclusão é mostrar que as crianças são capazes de realizar interações complexas, progredindo da negação e afirmação a formas de argumentação muito sofisticadas. A relevância do ponto de vista das próprias crianças é destacada por Passuth (1987), ao descrever as atitudes das crianças em relação à sua própria idade e à idade dos outros, assim como os privilégios e expectativas referentes aos comportamentos que são associados ao fato das crianças serem grandes ou pequenas.

Ainda no sentido de reforçar a capacidade de participação infantil, Sarmento $(2004,2005)$ argumenta que, a par das intensas mudanças por que passa o mundo, as representações, idéias e conceitos sobre as crianças também vêm se modificando rapidamente. Montandon (2001), neste mesmo sentido, aponta que a valorização da criança na condição de agente ativo na construção cultural passa a ocorrer de forma mais intensa, o que é indicado pela quantidade de trabalhos que concluem sobre: (1) a grande influência que as crianças têm nas vidas de seus pais ou familiares(Alwin, 1988; Desalvo, Zurcher \& Grotevant, 1986); (2) os efeitos que as instituições escolares têm na organização da vida infantil (Frones, 1994; Phadraig, 1994); e (3) a luta implícita e velada entre educadores e alunos pelo poder e pelo direito de expressão, respectivamente (MacLaren, 1997).

Esses estudos servem para indicar que existem critérios alternativos para definir a infância e as relações deste momento desenvolvimental do ser humano com a sociedade adulta. Tais critérios estão relacionados às habilidades para o exercício das funções necessárias, à capacidade individual para o exercício da autonomia e da iniciativa.

Uma abordagem sociocultural construtivista nos permite, assim, compreender o próprio desenvol- vimento do conceito de infância no contexto das sociedades e valorizar a capacidade das crianças em participar dos processos decisórios. É necessário, pois, refletir de forma mais profunda em como a adoção dos critérios de infância poderá promover maior aproximação entre crianças e adultos e suas formas de compartilhar projetos, responsabilidades e compromissos. Superar a concepção da incapacidade e da incompletude será fundamental aspecto para que a participação infantil se torne uma realidade social.

\section{Referências}

Adams, E., \& Ingham, S. (1998). Changing places: Children's participation in environmental planning. London: The Children's Society.

Alwin, D. F. (1988). Historical changes in parental orientations to children. In P. A. Adler \& P. Adler (Eds.), Sociological studies of child development (Vol. 3, pp. 65-86). Greenwich, CT: JAI Press.

Ariès, P. (1978). História social da criança e da família. Rio de Janeiro: LTC.

Bourdieu, P. (1989). O poder simbólico. Rio de Janeiro: Bertrand.

Boto, C. O. (2002). Desencantamento da criança: Entre a renascença e o século das luzes. In M. C. Freitas \& M. Kuhlmann (Orgs.), Os intelectuais na história da infância (pp. 11-60). São Paulo: Cortez.

Bujes, M. I. E. (2000). O fio e a trama: As crianças nas malhas do poder. Educação e Realidade, 4(1), 25-44.

Bronfenbrenner, U. (1986). Ecology of the family as a context for human development: Research perspectives. Developmental Psychology, 22, 723-742.

Bruner, J. (1997). Atos de significação. Porto Alegre: Artes Médicas.

Corsaro, W. A. (1979). Young children's conception of status and role. Sociology of Education, 52, 46-59.

Corsaro, W. A. (1986). Discourse processes within peer culture: From a constructivist to an interpretive approach to childhood socialization. In P. A. Adler \& P. Adler (Eds.), Sociological studies of child development (Vol. 1, pp. 81-104). Greenwich, CT: JAI Press. 
Corsaro, W. A., \& Eder, D. (1990). Children's peer cultures. Annual Review of Sociology, 16, 197-220.

Corsaro, W. A., \& Miller, P. J. (1992). Interpretive approaches to children's socialization. San Francisco: Jossey Bass.

Checkoway, B., Kameshwari, P., \& Finn, J. (1995). Youth participation in community planning: What are the benefits? Journal of Planning Education and Research, 14, 134-139.

Crowley, P. (1998). Participación infantil: Para una definición del marco conceptual. In B. A. Verazzi \& R. Benes (Orgs.), La participación de niños $y$ adolescentes en el contexto de convención sobre los derechos del niño: Visiones y perspectivas (pp. 9-16). Bogotá: UNICEF.

Cruz, L., Hillesheim, B., \& Guareschi, N. M. F. (2005). Infância e políticas públicas: Um olhar sobre as práticas psi. Psicologia \& Sociedade, $17(3), 42-49$.

Desalvo, F. J., Zurcher, L. A., \& Grotevant, H. (1986). Toward understanding the discipline process: The parent-child interaction model. In P. A. Adler \& P. Adler (Eds.), Sociological studies of child development (Vol.1, pp. 123-136). Greenwich, CT: JAI Press.

Escámez, J., \& Gil, R. (2003). O protagonismo na educação. Porto Alegre: Artmed.

Ferreira, A. B. H. (2004). Novo dicionário Aurélio da lingua portuguesa (3a ed.). Curitiba: Positivo.

Ferretti, C. J., Zibas, D. M. L., \& Tartuce, G. L. B. P. (2004). Protagonismo juvenil na literatura especializada e na reforma do ensino médio. Cadernos de Pesquisa, 34, 411-423.

Foucault, M. (1984). Microfísica do poder. Rio de Janeiro: Graal.

Francis, M., \& Lorenzo, R. (2002). Seven realms of children's participation. Journal of Environmental Psychology, 22, 157-169.

Frones, I. (1994). Dimensions of childhood. In J. Qvortrup, M. Bardy, G. Sgritta \& H. Wintersberger (Eds.), Childhood matters: Social theory, practice and politics (pp. 145-164). Aldershot, United Kingdom: Avebury.
Gélis, J. (1991). A individualização da criança. In P. Ariès \& R. Chartier (Orgs.), História da vida privada: Da Renascença ao século das luzes (pp. 311-329). São Paulo: Cia das Letras.

Hardman, C. (2001). Can there be an anthropology of children? Childhood, 8, 501-517.

Hart, R. (1992). Children's participation: From tokenism to citizenship. Florence, Italy: UNICEF

Hart, R. (1997). Children's participation: The theory and practice of involving young citizens in community development and environmental care. London: Earthscan.

Hill, M., Davis, J., Prout, A., \& Tisdall, K. (2004). Moving the participation agenda forward. Children \& Society, 18, 77-96.

Kirby, P., Lanyon, C., Cronin, K., \& Sinclair, R. (2003). Building a culture of participation. London: Department for Education and Skills.

Korczak, J. (1984). Como amar uma criança. São Paulo: Paz e Terra. (Original publicado em 1919).

Kramer, S. (2003). A política do pré-escolar no Brasil: A arte do disfarce (7a ed.). São Paulo: Cortez.

Kramer, S., \& Leite, M. I. (1996). Infância: Fios e desafios da pesquisa (3a ed.). Campinas, SP: Papirus.

MacLaren, P. (1997). A vida nas escolas: Uma introdução à pedagogia crítica nos fundamentos da educação. Porto Alegre: Artes Médicas.

Matthews, H., Limb, M., \& Taylor, M. (1999). Young people's participation and representation in society. Geoforum, 30, 135-144.

Maynard, D. (1986). The Development of argumentative skills among children. In P. A. Adler \& P. Adler (Eds.), Sociological studies of child development (Vol. 1, pp. 233-258). Greenwich, CT: JAI Press.

Montandon, C. (2001). Sociologia da infância: Balanço dos trabalhos em língua inglesa. Cadernos de Pesquisa, 112, 33-60.

Novaes, R. (2000). Juventude e participação social: Apontamentos sobre a reinvenção da política. In H. W. Abramo, M. V. Freitas \& M. P. Sposito (Orgs.), Juventude em debate (pp. 46-69). São Paulo: Cortez. 
Oswald, H. (1992). Negotiations of norms and sanctions among children. In P. A. Adler \& P. Adler (Eds.), Sociological studies of child development (Vol. 1, pp. 99-114). Greenwich, CT: JAI Press.

Passuth, P. M. (1987). Age hierarchies within children's groups. In P. A. Adler \& P. Adler (Eds.), Sociological studies of child development (Vol. 2, pp. 185-204). Greenwich, CT: JAI Press.

Phadraig, M. N. G. (1994). Day care-adult interests versus children's needs? A question of compatibility. In J. Qvortrup, M. Bardy, G. Sgritta \& H. Wintersberger (Eds.), Childhood matters: Social theory, practice and politics (pp. 77-100). Aldershot, United Kingdom: Avebury.

Qvortrup, J. (1991). Childhood as a social phenomenon: An introduction to a series of national reports. Vienna: European Centre for Social Welfare Policy and Research.

Qvortrup, J. (1995). Childhood in Europe: A new field of social research. In L. Chisholm, P. Büchner, H. H. Krüger \& M. du Bois-Reymond (Eds.), Growing up in Europe: Contemporany horizons in childhood and youth studies (pp. 7-21). New York: Walter de Gruyter.

Rogoff, B. (1995). Observing sociocultural activity on three planes: Participatory appropriation, guided participation, and apprenticeship. In J. V. Wertsch, P. Del Rio \& A. Alvarez (Eds.), Sociocultural studies of mind (pp. 139-163). Cambridge, United Kingdom: Cambridge Universtity Press.

Sarmento, M. J. (2000). Sociologia da infância: Correntes, problemáticas e controvérsias. Cadernos do Noroeste, 13(2), 145-164.

Sarmento, M. J. (2001). A globalização e a infância: Impactos na condição social e na escolaridade. In R. L. Garcia \& A. Leite Filho (Orgs.), Em defesa da educação infantil. Rio de Janeiro: DP\&A.

Sarmento, M. J. (2003). Imaginário e culturas da infância. Cadernos de Educação, 21, 51-69.

Sarmento, M. J. (2004). As culturas da infância nas encruzilhadas da 2 a modernidade. In M. J. Sarmento \& A. B. Cerisara (Orgs.), Crianças e miúdos: Perspectivas sóciopedagógicas da infância e educação (pp. 9-34). Porto, Portugal: Edições Asa.
Sarmento, M. J. (2005). Gerações e alteridade: Interrogações a partir da sociologia da infância. Educação \& Sociedade, 91, 361-378.

Save the Children. Kirklees Metropolitan Council. (1996). Children's participation pack: A practical guide for play workers. London: SCF.

Shier, H. (1996). Giving children a voice. London: Camden Social Services.

Shier, H. (2001). Pathways to participation: Openings, opportunities and obligations. Children \& Society, 15, 107-117.

Sinclar, R. (2004). Participation in practice: Making it meaningful, effective and sustainable. Children \& Society, 18, 106-118.

Treseder, P. (1997). Empowering children and young people. London: SCF.

Valsiner, J. (2005). Soziale und emotionale Entwicklungsaufgaben im kulturellen kontext. In J. Asendorpf \& H. Rauh (Eds.), Enzyklpädie der psychologie: Vol. 3. Soziale, emotionale und Personlichkeitsentwicklung. Góttingen, DE: Hogrefe.

Willow, C. (1997). Hear! Hear! Promoting children and young people's democratic participation in local government. London: Local Government Information Unit.

Artigo recebido em 13/06/2007.

Aceito para publicação em 22/08/2007.

Endereço para correspondência:

Sergio Fernandes Senna Pires. SQN 202 B1 C, apto 405. CEP: 70832-030, Brasília-DF, Brasil. Email: senna_pires@yahoo.com.br

Sergio Fernandes Senna Pires é Doutor em Psicologia pela Universidade de Brasília, consultor legislativo da Câmara dos Deputados.

Angela Uchoa Branco é Doutora em Psicologia, Professora Adjunta do Instituto de Psicologia da Universidade de Brasília, coordenadora do Laboratório de Microgênese nas Interações Sociais, pesquisadora do CNPq. 